\title{
Tuning and experimental evaluation of a likelihood-based engine knock controller
}

\author{
Andreas Thomasson, Lars Eriksson, Tobias Lindell, James C. Peyton Jones, \\ Jill Spelina and Jesse Frey
}

\section{Linköping University Post Print}

\section{Tweet}

N.B.: When citing this work, cite the original article.

(C)2013 IEEE. Personal use of this material is permitted. However, permission to reprint/republish this material for advertising or promotional purposes or for creating new collective works for resale or redistribution to servers or lists, or to reuse any copyrighted component of this work in other works must be obtained from the IEEE.

Andreas Thomasson, Lars Eriksson, Tobias Lindell, James C. Peyton Jones, Jill Spelina and Jesse Frey, Tuning and experimental evaluation of a likelihood-based engine knock controller, 2013, Proceedings of the 52nd IEEE Conference on Decision \& Control, 6849-6854.

http://dx.doi.org/10.1109/CDC.2013.6760974

Postprint available at: Linköping University Electronic Press http://urn.kb.se/resolve?urn=urn:nbn:se:liu:diva-105682 


\title{
Tuning and experimental evaluation of a likelihood-based engine knock controller
}

\author{
Andreas Thomasson, Lars Eriksson, Tobias Lindell, James C. Peyton Jones, Jill Spelina, Jesse Frey
}

\begin{abstract}
A new likelihood-based stochastic knock controller, that achieves a significantly improved regulatory response relative to conventional strategies, while also maintaining a rapid transient response is presented. Up until now it has only been evaluated using simulations and the main contribution here is the implementation and validation of the knock controller on a five cylinder engine with variable compression ratio. Furthermore, an extension of the fast response strategy and a re-tuning of the controller is shown to improve performance. The controller is validated with respect to its robustness to changes in engine operating condition as well as compression ratio. The likelihood-based controller is demonstrated in engine tests and compared to a conventional controller and it is shown that it is able to operate closer to the knock limit with less variations in control action without increasing the risk of engine damage.
\end{abstract}

\section{INTRODUCTION}

Engine torque as function of spark timing for a gasoline engine typically has the shape of a second degree polynomial, see the example in Fig. 1 from [1]. The spark timing which gives maximum torque is called Maximum Brake Torque (MBT) timing, and for the most efficient operation the engine would ideally always operate with MBT timing. In high load operating points this is often not possible due to engine "knock", where the unburned fuel mixture self ignites due to high pressure and temperature. This results in a shock wave that can be very damaging to the engine, especially at high speed and load, and also makes a knocking sound that even when not damaging, would not be accepted by a customer.

The problem of knock sensing [2, 3] and how to process knock signals to produce a knock intensity metric [4-10], is well covered in the literature. The knock control problem has been less treated. A common approach is that the controller respond deterministically to each cycle, retarding the spark significantly if a knock is detected and otherwise slowly advancing the spark toward MBT [11]. The spark timing will

A. Thomasson, L. Eriksson and T. Lindell is with the Division of Vehicular Systems at the Department of Electrical Engineering, Linköping University, Linköping, SE-581 83 Sweden \{andreast, larer, tobiasl\} @isy.liu.se

J. Peyton Jones is with the Center for Nonlinear Dynamics and Control and the Department of Electrical and Computer Engineering, Villanova University, Villanova, PA 19085 USA james. peyton-jones@villanova.edu

J. Spelina is with the Center for Nonlinear Dynamics and Control, Villanova University, Villanova, PA 19085 USA, and also with the Science, Technology, Engineering and Mathematics Division, Delaware County Community College, Media, PA 19063 USA jspelina@dccc.edu

J. Frey is with the Department of Mathematics and Statistics, Villanova University, Villanova, PA 19085 USA jesse.frey@villanova.edu

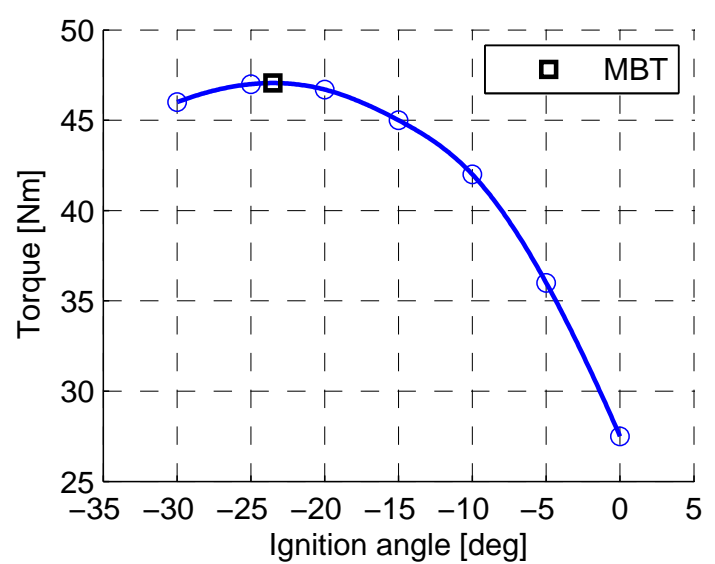

Fig. 1. Typical characteristic of torque as a function of spark advance.

therefore cycle back and forth, and on average be retarded compared to the knock limit.

Other approaches to knock control using statistical measures, controlling the mean or variance of knock intensity have been investigated [12, 13], but a parallel, fast-acting, conventional controller is often necessary to increase the speed up the response $[14,15]$. Another approach, using a cumulative-summation-based controller, has been presented in [16], and improved in [17, 18]. This controller reacts quickly to changes in knock rate while having less cyclic variability compared to the conventional controller, achieving a mean spark advance closer to the knock limit. An alternative stochastic controller using likelihood ratios was presented in [19], and further developed in [20], which has shown good performance in simulation.

\section{Contributions}

The likelihood-based knock controller has so far only been evaluated in simulation and the main contribution in this paper is the real-time implementation and experimental evaluation on a variable compression ratio engine. It strengthens earlier results, showing that the stochastic knock controller can operate closer to the optimal spark with less cyclic variability than a conventional controller. A further contribution is a re-tuning of the controller, coupled with an extension of the fast advance strategy which reduces the variance in the control actions even further. Engine transients are performed that demonstrate the controller performance for rapid changes in operating conditions. These investigations show that the advantages with this stochastic approach is achieved without compromising the speed of the transient response, compared to a conventional knock controller. 


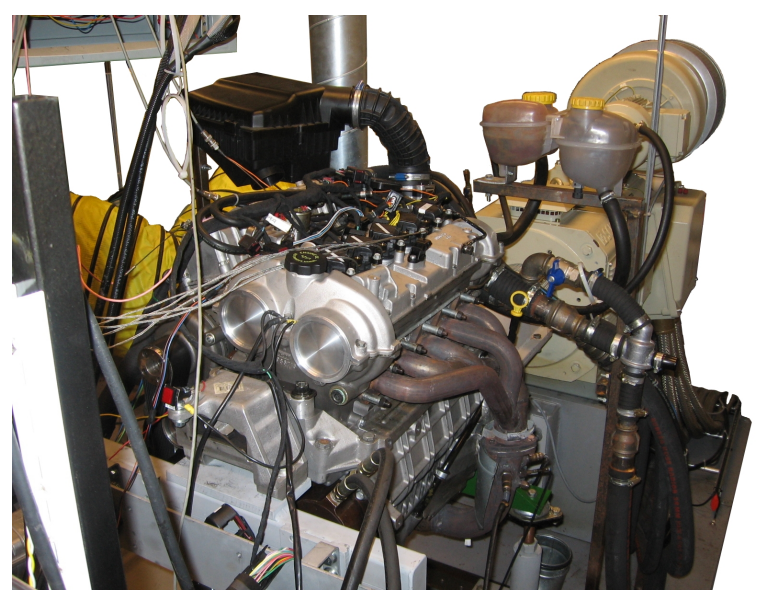

Fig. 2. The engine used for the experimental validation. It is a 5-cylinder, 1.61 gasoline engine, with variable compression in the range 8-14.5.

\section{EXPERIMENTAL SETUP}

Experiments are performed on a Saab Variable Compression (SVC) engine [21], which is a 5-cylinder 1.61 gasoline engine where the compression ratio can be varied from 8 to 14.5 , see Fig. 2 which shows the engine connected the electric dynamometer. The engine control system consists of a MicroAutoBox connected to a RapidPro-system from dSpace. The knock detection is made with a standard production knock sensor from Bosch. The threshold for the detection was calibrated by comparing the output from the knock sensor against cylinder pressure data, measured with cylinder pressure sensors from Kistler of type 6052.

\section{ENGINE KNOCK CHARACTERIZATION}

The basis for stochastic knock controller design is the assumption that knock intensity behaves as a cyclically independent random process. This was strengthened by the evaluation in [20] and will not be further treated here. Given the statistical independence of knock observations, the process can be completely characterized by the uni-dimensional probability density function (PDF) of the process.

The knocking characteristics of the SVC engine were therefore evaluated by operating the engine in open loop at a series of different spark advances spaced at 1 degree intervals around the "Borderline" spark condition at which knock first became audible to a trained technician. A PDF of the resulting knock intensities at each spark condition, normalized by the mean knock intensity at the Borderline condition, was then constructed as shown in Fig. 3, for cylinder 5. Inspection of the figure shows that the majority of cycles result in low knock intensities, but as the spark is advanced the distribution broadens and shifts to the right, and a larger portion of the distribution therefore falls in the high knock intensity region.

Although it is the high knock intensity cycles that are potentially damaging to the engine, it is important to note that it is not possible to control these cycles directly, any more than it is to control the outcome of any independent random event. It is only possible to control or select the distribution from which the knock intensities are drawn,

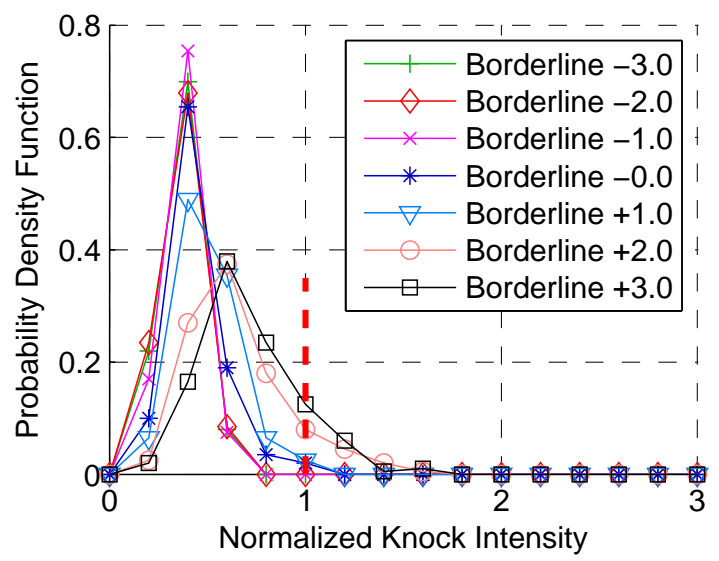

Fig. 3. Estimated knock intensity PDF's for different spark advance, on the SVC engine for cylinder 5.

according to the spark advance that is applied (see. Fig. 3). Many different measures of these distributions are possible, including standard statistical measures such as the mean, mode, or higher order moments of the distribution, but the near-uniform metric used in knock control applications is to evaluate the probability of knock intensities above some threshold value. This "knock event" probability $p$ corresponds to the area of the PDF above the threshold knock intensity (indicated by a dashed line in Fig. 3), but it can be estimated more directly from the data simply by counting the number of knock events $k$ observed in $N$ cycles of steady state operation, $p=k / N$.

Clearly the knock probability increases as the spark is advanced and more of the knock intensity distribution falls above the threshold. However, the probability distributions, and hence the knock event probability, may vary slightly from cylinder to cylinder within the same engine. The knock probability curves for each cylinder of the SVC engine used in this study are shown in Fig. 4. Most of the cylinders have a similar characteristic, with knock probability increasing as a function of spark advance, but the knock probability for cylinder 4 seems particularly sensitive to small changes in spark advance beyond Borderline conditions.

A few details are also worthy of comment. The threshold used to classify knock events was set such that $1 \%$ of cycles classified as knocking for cylinder 5 at Borderline audible knock conditions. The same threshold was applied to all cylinders, so the absolute angle of $1 \%$ Borderline knock varies slightly from cylinder to cylinder (see Table I). The knock probabilities shown in Fig. 4, are plotted relative to the individual "Borderline" spark angle which yielded the $1 \%$ knock rate. All the curves therefore have a $1 \%$ knock probability at 0 degrees relative to Borderline by definition. The aim of the knock controller is to maximize the spark advance while maintaining a $1 \%$ knock rate target. An ideal controller would therefore regulate the relative spark angle as closely as possible around the Borderline condition, returning to this condition rapidly when perturbed by some external event. 


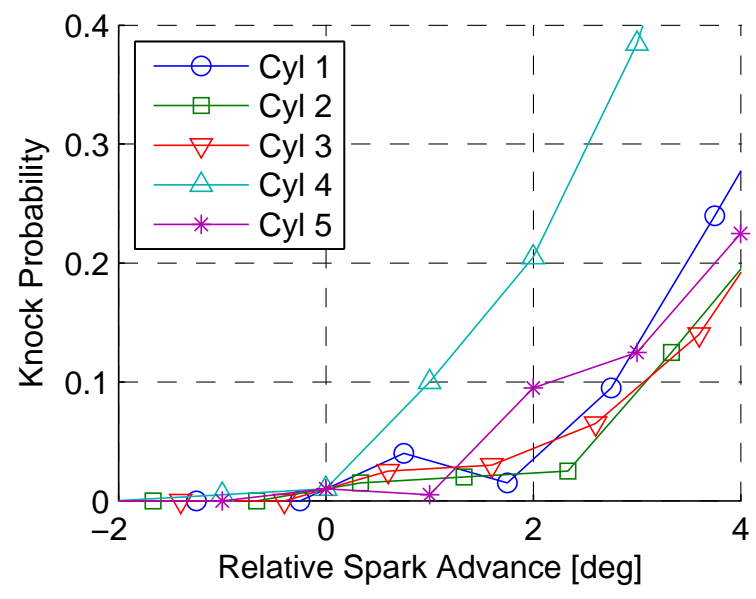

Fig. 4. Knock probability as function of spark advance for all cylinders.

TABLE I

BORDERLINE SPARK ADVANCE FOR THE OPERATING POINT IN FIG. 5

\begin{tabular}{lccccc}
\hline Cylinder & 1 & 2 & 3 & 4 & 5 \\
\hline Borderline & 16.2 & 16.9 & 17.0 & 11.3 & 14.2 \\
\hline
\end{tabular}

\section{Conventional Knock Control}

In order to establish a performance baseline for comparison, a conventional knock controller was implemented on the SVC engine. Such controllers slowly advance the spark by an amount $K_{\text {Adv }}$ each non-knocking cycle, but rapidly retard the spark by a much larger amount $K_{\text {Ret }}$ if a knock event does occur, [11]. The knock rate is determined by the ratio of these two gains, since for stable operation the advances must on average match the retards. This gives,

$$
K_{\text {Ret }} p=K_{\text {Adv }}(1-p)
$$

and therefore,

$$
p=\frac{K_{\mathrm{Adv}}}{K_{\mathrm{Ret}}+K_{\mathrm{Adv}}} \quad \text { or } \quad K_{\mathrm{Adv}}=\frac{p}{1-p} K_{\mathrm{Ret}}
$$

In this case, the controller was tuned with a typical retard gain of 1.5 degrees, and an advance gain of $K_{\mathrm{Adv}}=\frac{1.5}{99}$, which according to (2), should yield a $1 \%$ target knock rate. The resulting traces, (Fig. 5), show the classic sawtooth-like waveform associated with this type of controller, with the spark ramping up during knock free periods, and retarding sharply every time a knock event occurs (as indicated by a small dot in the figure). Although the target knock rate is achieved, the controller continually cycles in and out of knock rather than settling at the desired $1 \%$ Borderline spark advance condition (Table 1). This means that the mean spark advance is typically somewhat retarded relative Borderline as the controller compensates for the increased knock rate associated with the upper tail of this distribution (see Fig. 6). The relatively wide dispersion in applied spark angle also exacerbates any inherent cyclic variability in combustion.

\section{LIKELIHOOD-BASED KNOCK CONTROL}

The likelihood-based controller advocated in [20] addresses these issues by adjusting the spark angle only when there is sufficient statistical evidence that a control move

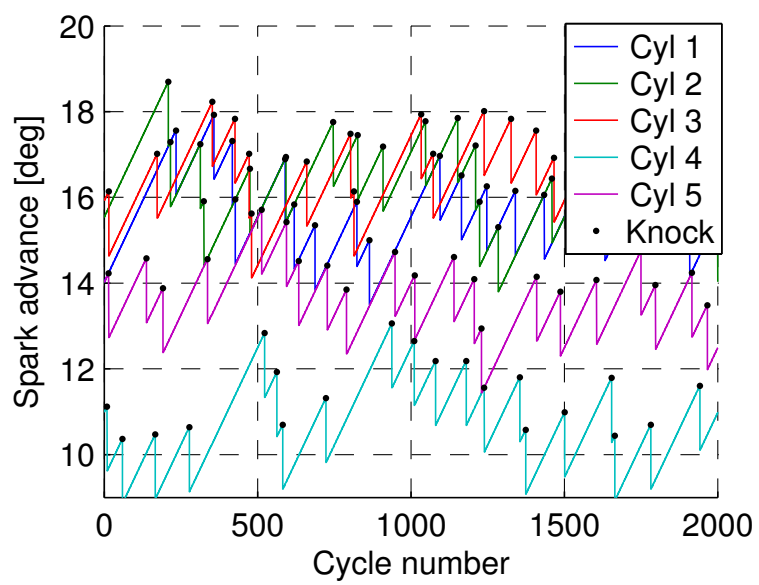

Fig. 5. Spark timing for the conventional knock controller during test at an engine speed of $1500 \mathrm{rpm}$, an intake pressure of $120 \mathrm{kPa}$ and compression ratio of 12 . The black dots indicate detected knock events.

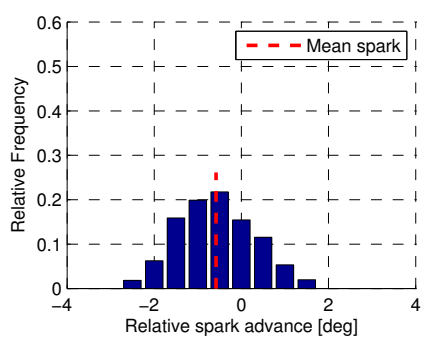

Fig. 6. Histogram of the closed loop spark advance for cylinder 1 with the conventional knock controller.

is necessary. The magnitude of these adjustments is also scaled according to the likelihood of the observations that are actually recorded from the engine. Simulation results suggest that this is a very promising approach, and the aim of this paper is to validate the method experimentally.

\section{A. The Algorithm and Background Theory}

The method is based on the observation that the binary classification of knock intensities into knocking and nonknocking cycles means that knock events are, by definition, binomially distributed regardless of the distribution of knock intensities. Given the knock probability, $p$, at any given spark advance, the probability of observing exactly $k$ knock events in $n$ cycles is therefore given by,

$$
P_{n}(k)=\left(\begin{array}{l}
n \\
k
\end{array}\right) p^{k}(1-p)^{n-k}
$$

From a control perspective, however, the absolute values of these probabilities is less meaningful than the ratio of the likelihood $P_{n}\left(k, p_{0}\right)$, evaluated using the target knock rate $p_{0}$, relative to the same likelihood $P_{n}\left(k, p_{\max }\right)$, evaluated using the maximum likelihood estimate of the current knock probability $p_{\max }=k / n$. This likelihood ratio may therefore be expressed as,

$$
L_{n}(k)=\frac{p^{k}(1-p)^{n-k}}{p_{\max }^{k}\left(1-p_{\max }\right)^{n-k}}
$$

where, in limiting cases, $0^{0}$ is defined to be 1 . 


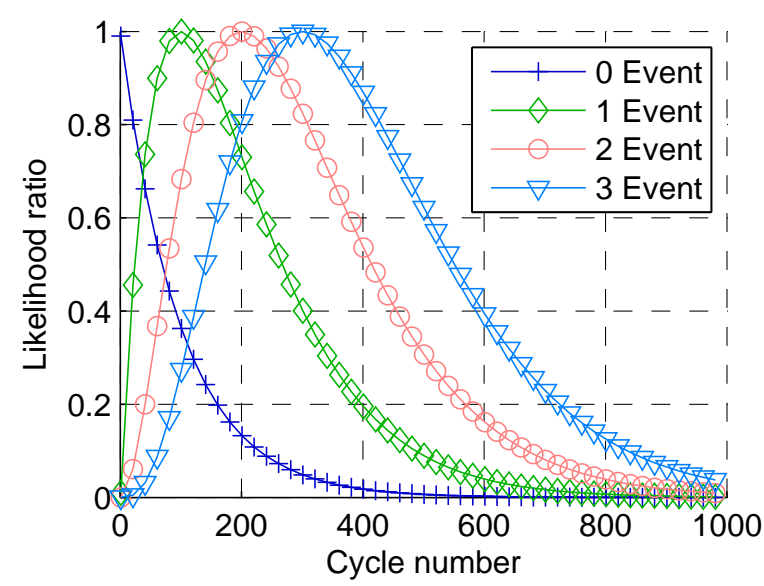

Fig. 7. Likelihood ratio as function of cycle number for different numbers of knock events $(p=0.01)$.

Fig. 7 shows a plot of the likelihood ratio as a function of cycle number, for $0,1,2$ and 3 knock events respectively, and for an assumed underlying knock rate, $p=0.01$. As seen from the figure, the likelihood ratio peaks at a value of 1 when the observations perfectly match the assumed knock rate, i.e. at $n=100$ for 1 knock event, at $n=200$ for 2 knock events etc. The likelihood ratio is also very small when there is an apparent mismatch between the observations and the target knock rate, as for example if three knock events all occurred in the first few cycles of observation, or if only one knock event had been observed after $n=1000$ cycles. Likelihood ratios falling below some given threshold therefore reflect a similar degree of evidence against the hypothesis that knock is occurring at the desired rate, and consequently a need for a spark adjustment. The magnitude of this adjustment can also be scaled by a factor $\left(1-L_{n}(k)\right)$ so that low likelihood ratio events result in a larger control action, and vice versa.

The control strategy outlined above is straightforward to implement in a real-time system. By counting the number of knock events and the total number of cycles since the last spark adjustment, it is easy to compute $p_{\max }$ and hence, from (4), the likelihood ratio for these observations. If this likelihood ratio falls below a given threshold, $L T$, then an advance or retard is made according to whether $p_{\max }$ is above or below the target knock rate. In this simple form, however, the controller can become insensitive to a sudden onset of knock events after a prolonged period at the desired target. This is remedied by evaluating the likelihood ratio for the most recent series of knock events. A short four-element First-In-First-Out (FIFO) buffer is used for this purpose. The first element stores the number of cycles that have passed without any knock events since the last spark adjustment was made, and the remaining three elements keep track of the cycle counts for the first, second and third most recent knock events respectively. The likelihood ratio is evaluated for each element in the buffer, and any value falling below the threshold is sufficient to trigger a spark adjustment.

While this takes care of the sensitivity to a sudden increase in knock rate, the response to an initially retarded spark is

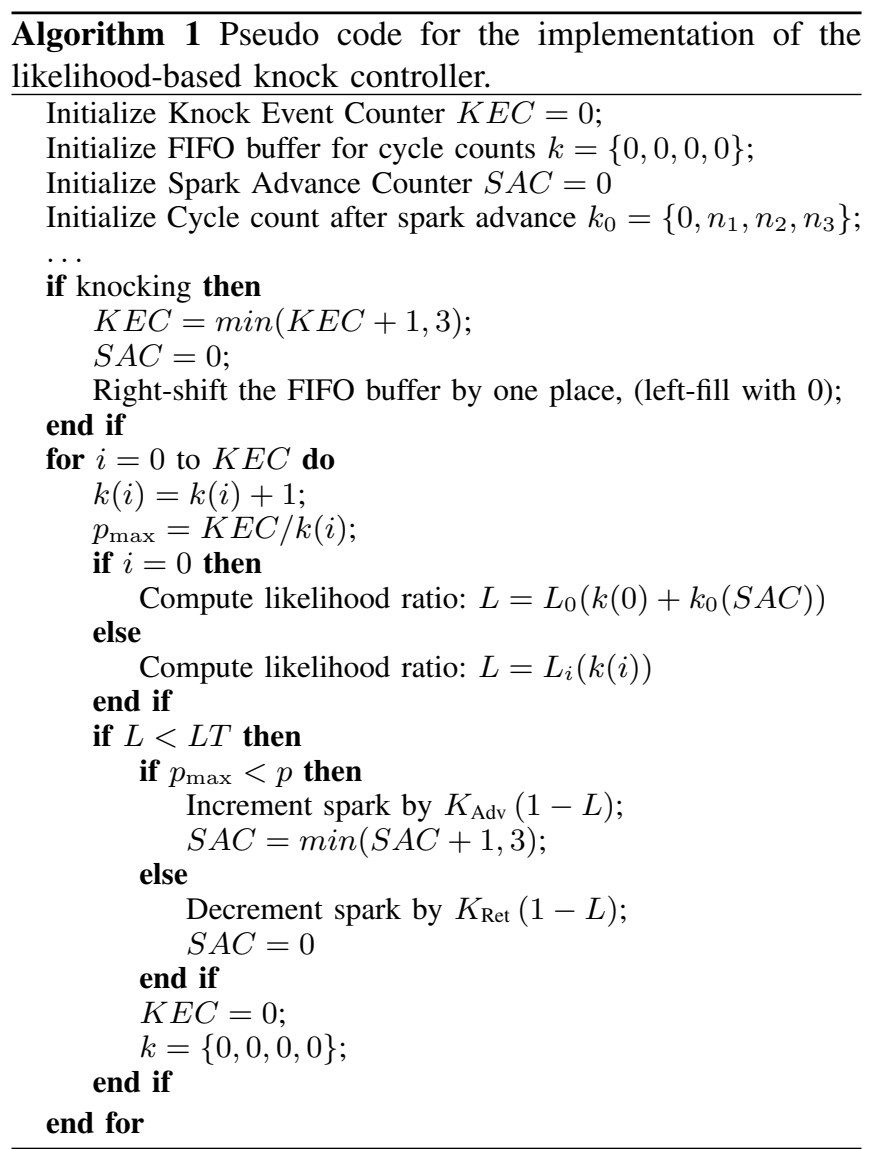

fairly slow. The reason for this can be seen from (4). For a likelihood threshold of 0.4 , for example, then inspection of the figure shows that at least 92 non-knocking cycles must elapse before the likelihood ratio falls below 0.4 and compensating adjustments are made. The fastest rate of spark advance adjustments is therefore once every 92 cycles. The proposed solution is to make the system more sensitive to repeated "advance" events by resetting the cycle count to some positive number after an "advance" event. This speeds up the repeat advance response by reducing the number of cycles before the non-knocking likelihood ratio threshold is triggered. The response to knocking events, meanwhile, is minimally affected.

In this paper the "fast advance" technique is extended by resetting the cycle count to a value which increases with the number of "repeat advance" adjustments that have been made without the occurrence of a single knock event. The reset cycle count is increased in three stages, after one, two and three spark advances with zero knock, so that the rate of spark advance increases until the first knock event occurs. With this slight modification, the algorithm presented in [19, 20] becomes as shown in Algorithm 1.

\section{B. Experimental evaluation}

The likelihood-based knock controller was implemented and tested on the system described in section II. Fig. 8 shows the spark advance for the likelihood controller in the same operating point as the conventional controller in Fig. 5. The 


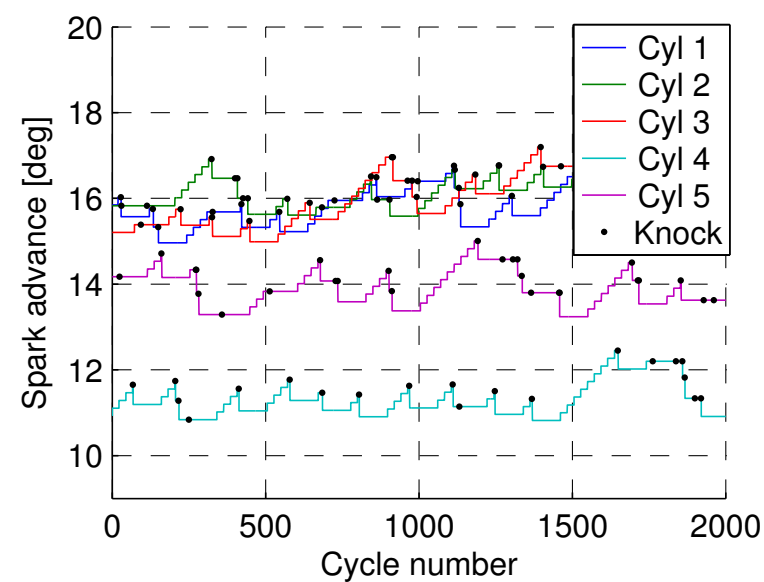

Fig. 8. Spark timing for the likelihood-based knock controller with tuning from [20] during test at an engine speed of $1500 \mathrm{rpm}$, an intake pressure of $120 \mathrm{kPa}$ and compression ratio of 12 .

parameter choice is the same as the final tuning in [20], $p=0.01, K_{\text {Adv }}=0.3, K_{\text {Ret }}=0.6$, Likelihood threshold 0.4 , and with reset cycle count after spark advance of 70 , corresponding to $k_{0}=\{0,70,70,70\}$ in Algorithm 1 . Compared to the conventional controller the knock rate is slightly higher, $1.08 \%$ and the spark advance slightly more advanced by 0.14 degrees. These two are fairly similar, but the standard deviation on the other hand is only about half that of the standard controller, 0.48 compared to 0.85 .

The likelihood controller is much less active than the conventional controller, although it can be seen in Fig. 8 that the spark is never constant over a prolonged series of time, despite lying close to the desire knock rate target. The reason this is not possible is that with $p=0.01$ and likelihood threshold 0.4, the controller will advance after 92 cycles with no knock, while aiming for 1 knock in 100 cycles. For the likelihood controller to be able to have a fixed spark the desired knock rate, the likelihood for zero knock events can not fall below the threshold before $1 / p$ cycles have passed, with some margin. By allowing more cycles with zero knock to pass before a spark advance, the controller becomes even less active, but the transient response to a decrease in knock rate will be slower. To counteract this, the increased cycle count after spark advance mentioned earlier, was implemented. This is represented by $k_{0}$ in Algorithm 1 . The controller parameters were also tuned. Fig. 9 shows the spark advance with $p=0.007, K_{\mathrm{Adv}}=0.4, K_{\mathrm{Ret}}=0.6$, likelihood threshold 0.35 and $k_{0}=\{0,50,90,130\}$. The mean spark advance is identical to the conventional controller and the knock rate slightly lower, $0.96 \%$. This tuning is less active than the previous, with a standard deviation of 0.4 , and can keep the spark constant when operating at the desired knock rate. The price for this is an initially slightly slower spark advance for initial conditions with retarded spark.

In Fig. 10 the histogram for the spark advance for one cylinder with the likelihood controller is shown. The left plot corresponds to the tuning in Fig. 8 and the right plot to the tuning in Fig. 9. In both cases the spark is controlled in a more narrow interval compared to the conventional

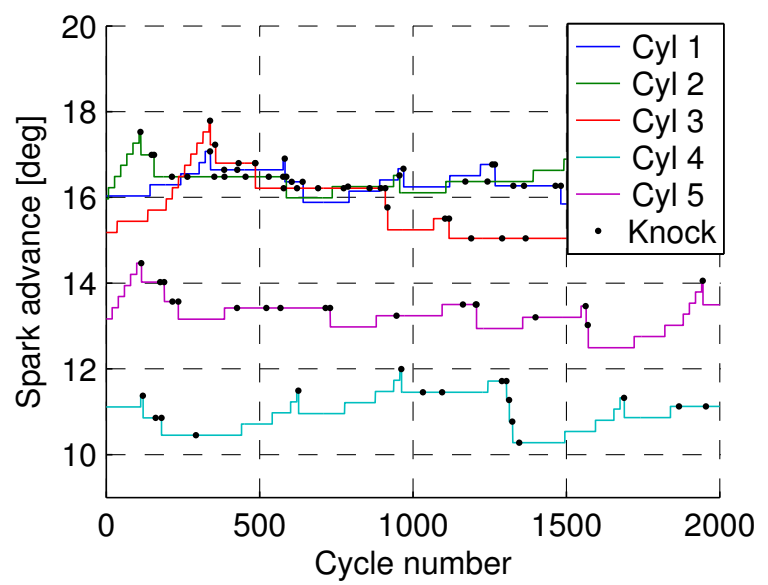

Fig. 9. Spark timing for the likelihood-based knock controller with improved tuning during test at an engine speed of $1500 \mathrm{rpm}$, an intake pressure of $120 \mathrm{kPa}$ and compression ratio of 12 .
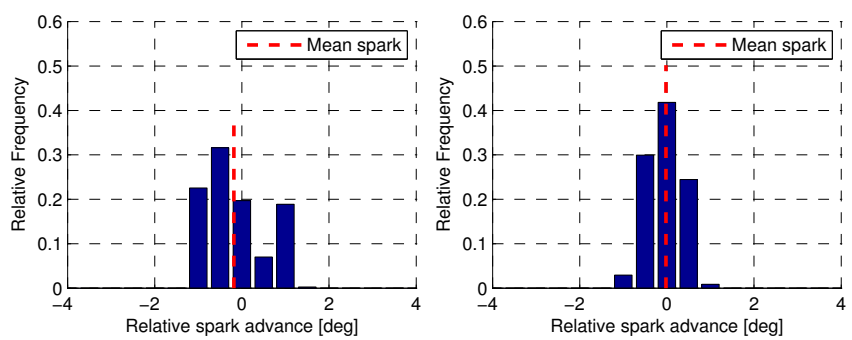

Fig. 10. Histogram of the closed loop spark advance for cylinder 1, the blue line in Fig. 8 (left) and Fig. 9 (right).

controller, see Fig. 6. Table II shows performance statistics of the conventional controller and the likelihood-based controller at three different operating points. With the initial parameterization, that was never tuned for this engine, the likelihood-based controller is able to operate at a better spark advance compared to the conventional controller, with only slightly higher knock rate. With only small amounts of retuning the controller receive equal or less knock rate.

The transient response of the controller is investigated by a tip-in experiment with a step from $100 \mathrm{kPa}$ to $140 \mathrm{kPa}$ intake manifold pressure. The resultant response for the conventional and the likelihood-based knock controller is shown in Fig. 11. The transient is done with no feedforward,

TABLE II

KNOCK CONTROLLER PERFORMANCE AVERAGED OVER ALL CYLINDERS

\begin{tabular}{|c|c|c|c|}
\hline Algorithm & Knock Rate [\%] & Mean Spark (wrt BL) & Std Spark \\
\hline \multicolumn{4}{|c|}{ Compression ratio 12 , Intake pressure $120 \mathrm{kPa}, 1500 \mathrm{rpm}$} \\
\hline Conventional & 1.01 & -0.6 & 0.85 \\
\hline Likelihood $^{1}$ & 1.08 & -0.5 & 0.48 \\
\hline Likelihood $^{2}$ & 0.96 & -0.6 & 0.41 \\
\hline \multicolumn{4}{|c|}{ Compression ratio 14 , Intake pressure $120 \mathrm{kPa}, 1500 \mathrm{rpm}$} \\
\hline Conventional & 0.99 & -0.6 & 0.84 \\
\hline Likelihood $^{1}$ & 1.24 & -0.1 & 0.37 \\
\hline Likelihood $^{2}$ & 0.80 & -0.2 & 0.33 \\
\hline \multicolumn{4}{|c|}{ Compression ratio 12 , Intake pressure $140 \mathrm{kPa}, 1500 \mathrm{rpm}$} \\
\hline Conventional & 0.99 & -0.6 & 0.87 \\
\hline Likelihood $^{1}$ & 1.22 & -0.6 & 0.50 \\
\hline Likelihood $^{2}$ & 1.00 & -0.5 & 0.50 \\
\hline
\end{tabular}



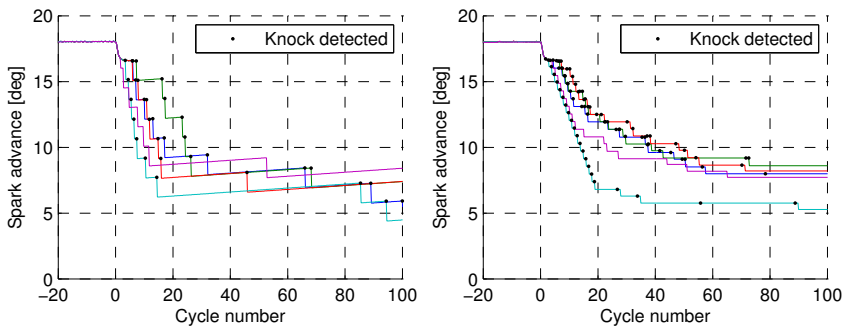

Fig. 11. Spark and knocking events for the conventional knock controller (left) and the re-tuned likelihood controller (right), during tip-in from $100 \mathrm{kPa}$ to $140 \mathrm{kPa}$ intake manifold pressure. The transient is done with no feedforward to highlight the speed of the feedback response.

that would otherwise take care of the major part of the step, to highlight the speed of the feedback response. Both controllers are similar with respect to the number of cycles it takes to reach the new operating point, but the conventional controller has fewer knock events during the transient.

\section{CONCLUSIONS}

A likelihood-based knock controller has been implemented in a real-time control system and tested on a variable compression ratio engine. The experimental evaluation confirms previous simulation results, showing that the stochastic controller can operate with more optimal spark and reduced cyclic variability compared to the conventional controller. A re-tuning of the controller, coupled with an extension of the fast advance strategy is proposed that further reduces cyclic variability, with the price of slightly slower initial spark advance for non knocking conditions. The re-tuned controller is shown to improve the performance in the experimental setup. Even though the likelihood-based controller has a smoother control action the tip-in experiments performed show that it achieves the same transient response performance as the conventional knock controller.

\section{REFERENCES}

[1] L. Eriksson, "Spark advance modeling and control," Ph.D. dissertation, Linköpings Universitet, May 1999.

[2] V. AG. and V. A. R. Division, Knocking of Combustion Engines: International Symposium, November 26-27, 1981, D-3180 Wolfsburg, Federal Republic of Germany. Wolkswagenwerk AG, 1981. [Online]. Available: http://books.google.se/books?id=8MPVGwAACAAJ

[3] S. Dues, J. Adams, , and G. Shinkle, "Combustion knocking sensing - sensor selection and application issues," in SAE paper 900488, 1990.

[4] X. Gao, R. Stone, C. Hudson, and I. Bradbury, "The detection and quantification of knock in spark ignition engines," in SAE paper 932759, 1993.

[5] T. Horner, "Knock detection using spectral analysis techniques of a texas instruments tms 320 dsp," in $S A E$ paper 960614, 1996.

[6] B. Samimy and G. Rizzoni, "Engine knock analysis and detection using time-frequency analysis," in SAE paper 960618, 1996.

[7] D. Scholl, S. R. T. Barash, and W. Stockhausen, "Spectrogram analysis of accelerometer-based spark knock detection waveforms," in SAE paper 972020, 1997.
[8] M. Brunt, C. Pond, and J. Biundo, "Gasoline engine knock analysis using cylinder pressure data," in $S A E$ paper 980896, 1998.

[9] J. Naber, J. Blough, D. Frankowski, M. Goble, and J. Szpytman, "Analysis of combustion knock metrics in spark-ignition engines," in SAE paper 2006-01-0400, 2006.

[10] Y. Nilsson, E. Frisk, and L. Nielsen, "Weak knock characterisation and detection for knock control," Institution of Mechanical Engineers, Part D: Journal of Automobile Engineering, vol. 223, no. 1, pp. 107-129, 2009.

[11] U. Kiencke and L. Nielsen, Automotive Control Systems, For Engine, Driveline, and Vehicle, 2nd ed. Springer Verlag, 2005.

[12] K. Schmillen and M. Rechs, "Different methods of knock detection and knock control," in SAE paper 910858, 1991.

[13] M. Pennese, F. D. A. Bucci, , and G. Montanari, "Sigma ő on knock phenomenon control of flex fuel engines," in SAE paper 2005-01-3990, 2005.

[14] N. Cavina, G. Po, and L. Poggio, "Ion current based spark advance management for maximum torque production and knock control," in Proc. Eighth Biennial ASME Conference on Engineering Systems Design and Analysis, 2006, pp. 537-545.

[15] G. Zhu, I. Haskara, and J. Winkelman, "Stochastic limit control and its applications to spark limited control using ionization feedback," in Proc. 2005 American Control Conference, 2005, pp. 5027-5034.

[16] J. Peyton Jones, J. Frey, K. Muske, , and D. Scholl, "A stochastic knock control algorithm," in SAE paper 2009-01-1017, 2009.

[17] J. Peyton Jones, J. Frey, and K. Muske, "A fast-acting stochastic approach to knock control," in Proc. IFAC Workshop on Engine Powertrain Control, Simulation and Modeling, IFP, France, 2009.

[18] J. Peyton Jones, J. Frey, K. Muske, and D. Scholl, "A cumulative-summation-based stochastic knock controller," in Proceedings of the Institution of Mechanical Engineers, Part D: Journal of Automobile Engineering, vol. 224, no. 7, 2010, pp. $969-983$.

[19] J. Peyton Jones, J. Frey, and K. Muske, "A statistical likelihood based knock controller," in Proc. 6th IFAC Symposium Advances in Automotive Control, Munich, Germany, 2010, pp. 809 - 814.

[20] J. Peyton Jones, J. M. Spelina, and J. Frey, "Likelihoodbased control of engine knock," IEEE Transaction on Control Systems Technology, vol. PP, no. 99, 2013, doi:10.1109/TCST.2012.2229280.

[21] H. Drangel, E. Olofsson, and R. Reinmann, "The variable compression (SVC) and the combustion control (SCC)-two ways to improve fuel economy and still comply with world-wide emission requirements," $S A E$ Technical Paper 2002-01-0996, 2002. 